\title{
The Role of Ultrasound in Assessment of Diaphragmatic Dysfunction in I.C.U Patients
}

\author{
Islam M. Alshaer $^{\mathrm{a}}$, Hesham E. Elsheikh ${ }^{\mathrm{a}}$, Ahmed E. Shaalan ${ }^{\mathrm{a}}$, Marwa E. Elnaggar ${ }^{\mathrm{b}}$
}

\begin{abstract}
a Department of Radiology, Benha faculty of medicine, Banha university, Egypt. department of chest medicine, Benha faculty of Medicine, Benha University, Egypt
\end{abstract}

Correspondence to: Islam $\mathrm{M}$. Alshaer, department of Radiology, Faculty of medicine, Banha university, Egypt Egypt

Email:

islamshaer@gmail.com

Received: 24 September 2019

Accepted: 1 December 2019

\section{Abstract:}

Background: Diaphragm dysfunction (DD) is frequently seen in critically ill patients, and ultrasound could be a useful tool to detect it and to predict extubation success or failure in mechanically ventilated patients. Besides, it would also be useful in differential diagnosis of dyspnea and respiratory failure. Aim of work :The aim of work is to evaluate usefulness and accuracy of ultrasound in assessment of DD in intensive care unit (ICU) patients in comparison with clinical outcome of patients.. In this prospective study, we compared the performance of ultrasound in visualization of diaphragm, detection of paradoxical movement, measurement of tidal and maximal thickness, and excursion, and calculation of thickening fraction $(\mathrm{TF})$ of the diaphragm in quiet breathing. Patients and Method: The present study was performed on50 patients (26 males and 24 females) admitted in RICU in Benha university hospital The field study was conducted from March 2019 to September 2019. Ultrasound of the Rt, hemidiaphragm was done on the day of admission or soon after admission (1-2) days. Results: there was no statistical significant difference between the studied groups regarding ultrasound measurement (DTF, DE and DT) and patient outcome with p value $(0.273,0.245$ and 0.497$)$ respectively .Conclusion: ultrasound of diaphragm in ICU patients may be a reliable, noninvasive and convenient way to assess the DD in ICU patients to predict their outcome.

Key words: Diaphragm ultrasound; Diaphragm Dysfunction; Diaphragm Excursion; Diaphragm Thickness 


\section{Introduction}

The diaphragm is the principal respiratory muscle. With an excursion of 1 to $2 \mathrm{~cm}$, the diaphragm provides nearly $75 \%$ of the resting pulmonary ventilation, while during the forced breathing, its amplitude is up to 7 to $11 \mathrm{~cm} .(1)$. Abnormal diaphragmatic motion is observed in conditions such as phrenic nerve injury, neuromuscular diseases, after abdominal or cardiac surgery and in critically ill patients under mechanical ventilation(2.3)], in addition the diaphragm is vulnerable to damage from hypotension, hypoxia, and sepsis, all of which are very common in critically ill patients. While in surgical patients, diaphragm dysfunction is often caused by acute insults such as trauma or surgical procedures. In addition, mechanical ventilation itself can decrease the force of the diaphragm and induce diaphragmatic dysfunction, named as ventilator-induced diaphragmatic dysfunction (4.5).

Diaphragm dysfunction is responsible for a number of pulmonary complications, an early diagnosis of diaphragm dysfunction (before extubation) is mandatory to avoid weaning failure (6).

including atelectasis and pneumonia, which are risk factors for extubation failure. Hence, The use of tools previously available for assessment of diaphragmatic dysfunction is limited due to the associated risks of ionizing radiation (fluoroscopy, computed tomography) or due to their complex and/or highly specialized nature, requiring a skilled operator (transdiaphragmatic pressure measurement, diaphragmatic electromyography, phrenic nerve stimulation, magnetic resonance imaging (7) Bedside Ultrasonography US has become a valuable tool in the management of intensive care unit patients. Fig. 1,2 (8). This is especially true in emergency situations where an adequate imaging technique is frequently limited by a variety of factors, including difficulty of patient transportation to the radiology department due to illness severity .US is a noninvasive technique, which has proved to be an accurate, safe, easy to use bedside modality, overcoming many of the standard limitations of imaging techniques.(9) 

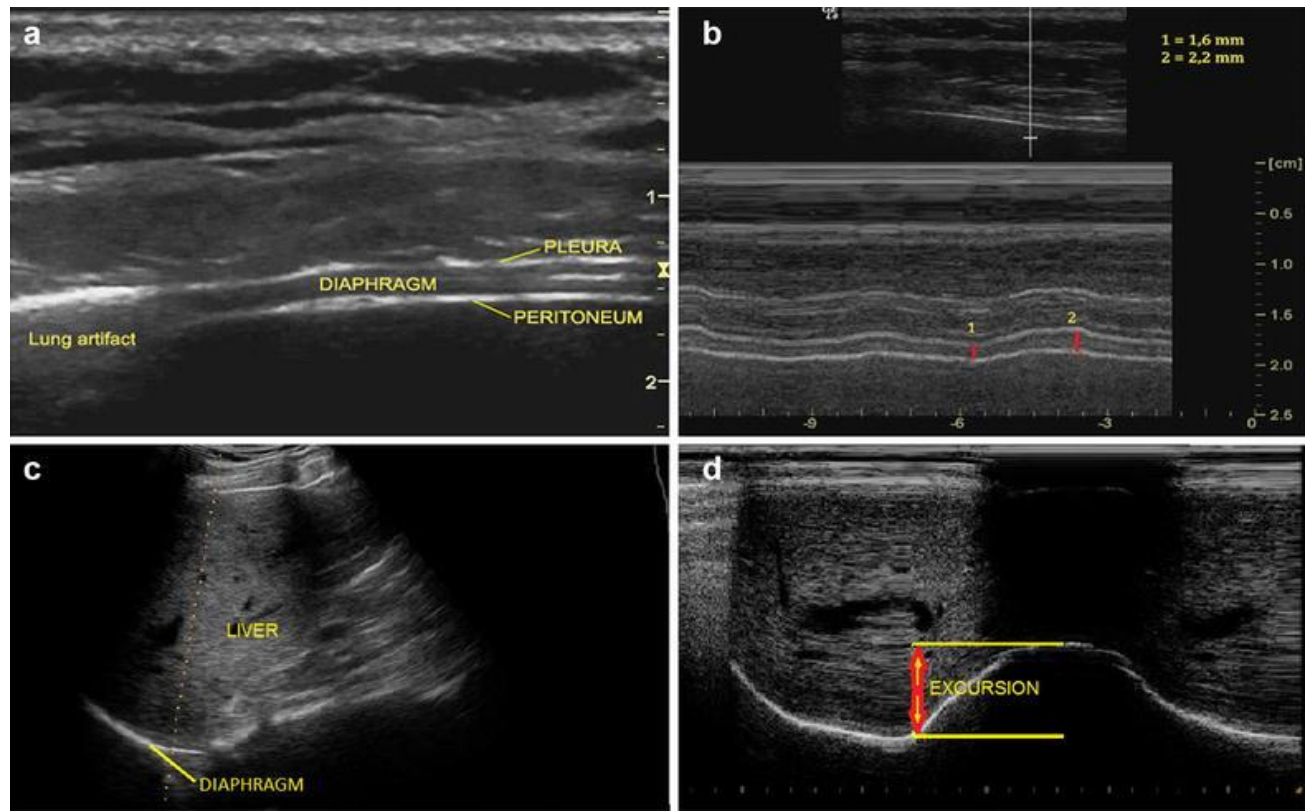

Fig.(1): Diaphragm ultrasonography (DU) at the zone of apposition in a B-mode, b M-mode. 1 Thickness at end expiration, 2 thickness at end inspiration.DU, right subcostal in $\mathbf{c}$ B-mode, $\mathbf{d}$ M-mode
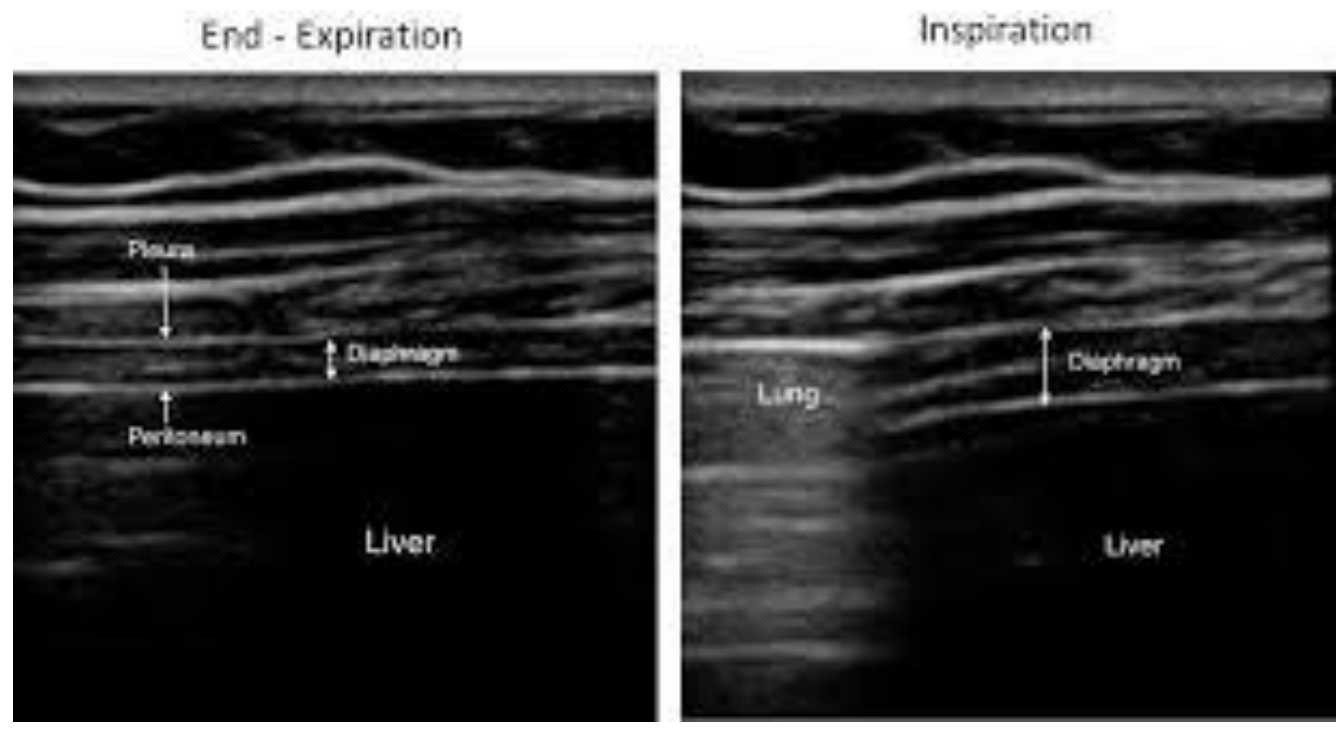

(Fig.2): Ultrasound image of diaphragm showing change in thickness during inspiration and expiration(8)

\section{Aim of The work:}

The aim of this work is to evaluate the role of US in assessment of diaphragmatic dysfunction in ICU patients.

\section{Patients and method:}

This prospective study was performed aiming to determine the role of ultrasound in diagnosis of diaphragm dysfynction and prediction of patient outcome 


\section{Study population}

- The study was conducted on $\mathbf{5 0}$ patients (26 male $52 \%$ and 24 .female $48 \%$ )

- Those patients were admitted to the Respiratory intensive care unit (RICU) in chest department Benha University Hospital .during the period between March 2019 and September2019.

- The study was approved by the Ethical Clearance Committee of Benha university.

- Informed consent was obtained from all patients or their relatives

- The same investigator performed all the recordings

- Diaphragm thickness and excursion (via Bmode ultrasonography) was measured done by ultrasound machine PHILIPS HD5 on the day of admission or soon after admission (1-2) days.

- The whole ultrasound examination was accomplished $\operatorname{In}(20-25)$ min

- Only the right hemidiaphragm was studied, as the limited acoustic window offered by the spleen does not always allow obtaining clear images on the left; intestinal or gastric gas may also interfere with imaging of the left diaphragmatic dome.

\section{Inclusion criteria:}

1. Patients admitted to I.C.U. with clinical suspicion of diaphragmatic dysfunction who will undergo detailed US for diaphragm.

2. The patients will approve to participate in the study

\section{Exclusion criteria:}

1. Patients admitted to I.C.U. with no clinical suspicion of diaphragmatic dysfunction .

2. Patients admitted to I.C.U. with clinical suspicion of diaphragmatic dysfunction who will undergo detailed US for diaphragm and refuse to participate in the study

3. Hemodynamically unstable patient.

\section{Methods:}

All the following data were collected for each patient

- Complete history taking including medical and surgical history.

- Complete physical examination (General and Chest examination).

- Laboratory evaluation

- Real-time thickness of the diaphragm was recorded by B- mode ultrasonography using $10 \mathrm{MHz}$ linear transducer. Diaphragmatic excursion should be measured with a lower frequency curvilinear probe (we used a 3-5 MHz probe) in anterior subcostal view. 


\section{Results:}

This prospective study included 50 patients(26 males 52\% and 24 female $48 \%$ ) who were admitted to the Respiratory intensive care unit (RICU) in chest department Benha University Hospital .during the period between March 2019 and September2019.

Data management and statistical analysis were performed using the Statistical Package for Social Sciences (SPSS) version 24. Numerical data were summarized using means and standard deviations or medians and ranges. Data were explored for normality using Kolmogrov-Smirnov test and ShapiroWilk test. Categorical data were summarized as percentages. Comparisons between the 2 groups with respect to normally distributed numeric variables were done using the independent t-test. Non-normally distributed numeric variables were compared by MannWhitney test. For categorical variables, differences were analyzed with $\chi^{2}$ (Chi square) test and Fisher's exact test when appropriate. All p-values are two-sided. Pvalues $\leq 0.05$ were considered significant Roc curve were used to detect cut off point that will determine the bad outcome.

The results of the study will be presented under the following sections:

1. Socio-Demographic characteristics of the participants.

2. vital signs and laboratory results
3. Radiological results

4. Factors affecting patients' outcome

Roc curve to detect cut off point for Radiological measures effect on patients outcome

\section{Socio-Demographic characteristics of the participants.}

The mean age of cases was $62.1 \pm 17.8$ year ranging from 17 to 85 years. Female represented the majority of cases $52 \%$. The mean duration of ICU stay was a $(13.5 \pm 9.3$ day) ranging from (3 to 47). Forty four patients had comorbid diseases; 16 (32\%) had DM, 14 patients $28 \%$ had COPD or ILD and 6 patients (12\%) had DVT. The main cause of admission in ICU was pneumonia (24 patients; 48\%).followed by ARF 14 patients $28 \%$ then COPD 11 patients $22 \%$, the last is pulmonary embolism 4 patients $8 \%$. The majority of cases (40 patients; 80\%) discharged from ICU to chest department ward and (10 patients $20 \%$ died), table (1), fig $3,4,5$.

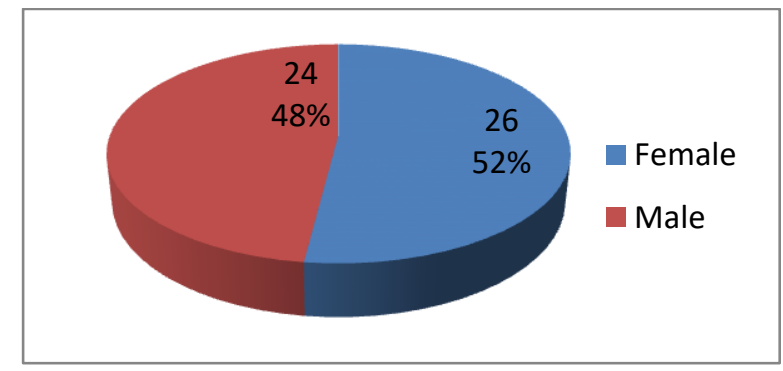

Fig.(3): pie chart representing gender distribution of the studied patients 


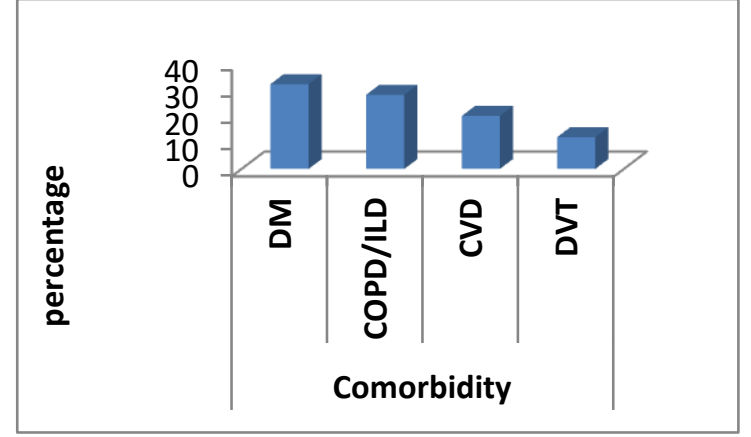

Fig.(4): Bar chart representing comorbidity distribution of the studied patients

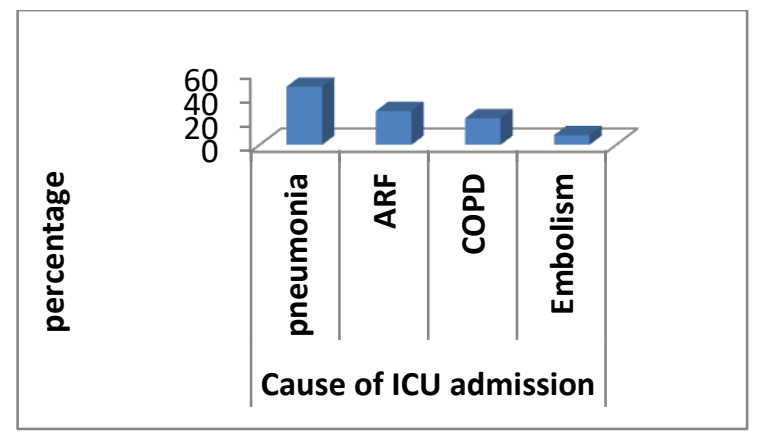

Fig.(5): Bar chart representing causes of ICU admission of the studied patients

\section{2. vital signs and laboratory results}

The mean systolic blood pressure was $116 \pm 15$. with range100 to160 The mean diastolic blood pressure was $73 \pm 1$ with range 60 to 100 . The mean temperature was $37.4 \pm 0.9$. with range 36.5 to 40.5 The mean pulse was $90 \pm 12$ with range 65 to 120 The mean respiratory rate was $25 \pm 6$. with range 13 to 45 (table 2,3).

\section{Radiological results.}

The mean DTF was $54.25 \pm 31.38$ with range 9.21 to 132.5 . The mean diaphragmatic US excursion was $1.05 \pm 0.50$ with range 0.33 to 2.42. The mean Diaphragmatic US thickening was $0.193 \pm 0.08$ with range 0.062 to 0.407 (table 4).

\section{Factors affecting patients' outcome.}

Demographic: All the demographic factors were comparable between the discharged and died group of patients as shown in table (5). In died patients $29.4 \%$ had no hypertension compared to none with hypertension; this was statistically significant $(\mathrm{p}=0.015)$.

Vital signs: All the vital signs were comparable between the discharged and died group of patients as shown in table (6).

Laboratory findings: All the lab results were comparable between the discharged and died group of patients as shown in table (7). For platelets: there was statistically significant decrease in the dead patients For pco2: there was statistically significant decrease in the dead patients For creatinine : there was statistically significant increase in the dead patients

US findings: All the US findings were comparable between the discharged and died group of patients as shown in table (8), fig 4,5 .

Roc curve to detect cut off point for Radiological measures effect on patients outcome:

All the radiological findings can't discriminate the outcome of patients (p>0.05), (table 9, 10,11), (fig. 6,7,8) 
Table (1): Demographic data of the studied patients $(n=50)$

\begin{tabular}{|c|c|c|c|c|}
\hline & & Count & $\%$ & \\
\hline \multirow[t]{2}{*}{ Age (years) } & Mean \pm SD & & $62.1 \pm 17.8$ & \\
\hline & Range & & $17-85$ & \\
\hline \multirow[t]{2}{*}{ Gender } & Female & 26 & & 52.0 \\
\hline & Male & 24 & & 48.0 \\
\hline \multirow[t]{5}{*}{ Comorbidity* } & yes & 44 & & 88.0 \\
\hline & $\mathrm{DM}$ & 16 & & 32.0 \\
\hline & COPD/ILD & 14 & & 28.0 \\
\hline & DVT & 6 & & 12.0 \\
\hline & CVD & 10 & & 20.0 \\
\hline \multirow[t]{4}{*}{ Cause of ICU admission* } & Embolism & 4 & & 8.0 \\
\hline & pneumonia & 24 & & 48.0 \\
\hline & $\mathrm{ARF}$ & 14 & & 28.0 \\
\hline & COPD & 11 & & 22.0 \\
\hline \multirow[t]{2}{*}{ Outcome } & Discharged & 40 & & 80.0 \\
\hline & Died & 10 & & 20.0 \\
\hline \multirow[t]{2}{*}{ Duration of stay (days) } & Mean \pm SD & \multicolumn{3}{|c|}{$13.5 \pm 9.3$} \\
\hline & Range & \multicolumn{3}{|c|}{$3-47$} \\
\hline
\end{tabular}

SD: standard deviation, DM; diabetes mellitus, HTN: hypertension,........*: patients may have more than one

Table (2): Vital signs in the studied patients $(n=50)$

\begin{tabular}{lccccc}
\hline & Mean & SD & Median & Minimum & Maximum \\
\hline BP. Systolic & 116 & 15 & 110 & 100 & 160 \\
BP. Diastolic & 73 & 11 & 70 & 60 & 100 \\
T & 37.4 & 0.9 & 37 & 36.5 & 40.5 \\
P & 90 & 12 & 90 & 65 & 120 \\
RR & 25 & 6 & 23 & 13 & 45 \\
\hline
\end{tabular}

Table (3): laboratory results in the studied patients $(n=50)$

\begin{tabular}{lccccc}
\hline & Mean & SD & Median & Minimum & Maximum \\
\hline WBC $(\mathbf{x 1 0} / \mathbf{c c})$ & 10.99 & 4.77 & 10.2 & 4.6 & 23.3 \\
Hb $(\mathbf{g m} / \mathbf{d l})$ & 11.9 & 2.3 & 11.8 & 6.9 & 17.2 \\
HCT & 34 & 6.9 & 33 & 19.7 & 50.8 \\
PLT $(\mathbf{x 1 0} / \mathbf{c c})$ & 241 & 100 & 222 & 62 & 534 \\
pH & 7.35 & 0.09 & 7.35 & 7.14 & 7.49 \\
PO2 & 66.1 & 14.2 & 66 & 35 & 92 \\
PCO2 & 42.4 & 19.4 & 39 & 24 & 117 \\
NaCH3 & 24.5 & 11.5 & 21 & 9 & 63 \\
SaO2\% & 86.9 & 10.6 & 91 & 62 & 97 \\
Urea (mg/d) & 74 & 63 & 41 & 18 & 285 \\
creat. $(\mathbf{m g} / \mathbf{d l})$ & 2.09 & 1.98 & 1.3 & 0.7 & 10 \\
Ka $(\mathbf{m E q} / \mathbf{L})$ & 4.4 & 1 & 4.4 & 3.1 & 7.7 \\
Na $(\mathbf{m E q} / \mathbf{L})$ & 138 & 5 & 139 & 129 & 145 \\
& & & & & \\
\hline
\end{tabular}


Table (4): US results in the studied patients $(n=50)$

\begin{tabular}{|c|c|c|c|c|c|}
\hline & Mean & SD & Median & Minimum & Maximum \\
\hline$\overline{\text { DTF }}$ & 54.25 & 31.38 & 43.58 & 9.21 & 132.5 \\
\hline $\begin{array}{l}\text { Diaphragmatic US excursion } \\
(1-2 \mathrm{~cm})\end{array}$ & 1.05 & 0.505 & 1.055 & 0.327 & 2.42 \\
\hline $\begin{array}{l}\text { Diaphragmatic US } \\
\text { thickening }(0.24+/-0.08 \mathrm{~cm} 4)\end{array}$ & 0.193 & 0.08 & 0.186 & 0.062 & 0.407 \\
\hline
\end{tabular}

Table ( 5): Demographic factors, comorbidities and cause of admission effect on patients outcome $(\mathrm{n}=50)$

\begin{tabular}{|c|c|c|c|c|c|c|}
\hline & & \multicolumn{2}{|c|}{$\begin{array}{l}\text { Discharged- Improved } \\
(\mathrm{n}=40)\end{array}$} & \multicolumn{2}{|c|}{$\begin{array}{c}\text { Died } \\
(n=10)\end{array}$} & \multirow[b]{2}{*}{ p value } \\
\hline & & Count & $\%$ & Count & $\%$ & \\
\hline Age (yrs.) & Mean \pm SD & \multicolumn{2}{|c|}{$61.0 \pm 18.9$} & \multicolumn{2}{|c|}{$66.4 \pm 12.4$} & 0.397 \\
\hline \multirow[t]{2}{*}{ Gender } & Female & 20 & 76.9 & 6 & 23.1 & 0.571 \\
\hline & Male & 20 & 83.3 & 4 & 16.7 & \\
\hline \multirow[t]{2}{*}{ Comorbidity } & No & 6 & 100.0 & 0 & 0.0 & $0.327^{\mathrm{a}}$ \\
\hline & Yes & 34 & 77.3 & 10 & 22.7 & \\
\hline \multirow[t]{2}{*}{ DM } & No & 26 & 76.5 & 8 & 23.5 & 0.363 \\
\hline & Yes & 14 & 87.5 & 2 & 12.5 & \\
\hline \multirow[t]{2}{*}{ HTN } & No & 24 & 70.6 & 10 & 29.4 & 0.015 \\
\hline & Yes & 16 & 100.0 & 0 & 0.0 & \\
\hline \multirow[t]{2}{*}{ COPD/ILD } & No & 30 & 83.3 & 6 & 16.7 & 0.345 \\
\hline & Yes & 10 & 71.4 & 4 & 28.6 & \\
\hline \multirow[t]{2}{*}{ DVT } & No & 34 & 77.3 & 10 & 22.7 & $0.327^{\mathrm{a}}$ \\
\hline & Yes & 6 & 100.0 & 0 & 0.0 & \\
\hline \multirow[t]{2}{*}{ CVD } & No & 32 & 80.0 & 8 & 20.0 & 1.000 \\
\hline & Yes & 8 & 80.0 & 2 & 20.0 & \\
\hline \multirow[t]{2}{*}{ Embolism } & No & 36 & 78.3 & 10 & 21.7 & $0.571^{\mathrm{a}}$ \\
\hline & Yes & 4 & 100.0 & 0 & 0.0 & \\
\hline \multirow[t]{2}{*}{ Pneumonia } & No & 22 & 84.6 & 4 & 15.4 & 0.396 \\
\hline & Yes & 18 & 75.0 & 6 & 25.0 & \\
\hline \multirow[t]{2}{*}{$\mathbf{A R F}$} & No & 28 & 77.8 & 8 & 22.2 & 0.529 \\
\hline & Yes & 12 & 85.7 & 2 & 14.3 & \\
\hline \multirow[t]{2}{*}{ COPD } & No & 32 & 82.1 & 7 & 17.9 & 0.495 \\
\hline & Yes & 8 & 72.7 & 3 & 27.3 & \\
\hline $\begin{array}{l}\text { Duration of } \\
\text { ICUstay }\end{array}$ & Median(range) & \multicolumn{2}{|c|}{$12(3-47)$} & \multicolumn{2}{|c|}{$11(5-18)$} & 0.284 \\
\hline
\end{tabular}

SD: standard deviation, $\mathrm{p} \leq 0.05$ is statistically significant, analysis done by Chi square test, a: analysis done by fisher exact test

Table (6): vital signs effect on patients outcome $(n=50)$

\begin{tabular}{lccccc}
\hline & \multicolumn{2}{c}{ Discharged- Improved } & Died & \\
& Mean & SD & Mean & SD & p value \\
\hline BP Systolic /mm & 117 & 17 & 114 & 5 & 0.645 \\
BP Diastolic /mm & 74 & 12 & 68 & 8 & 0.133 \\
Temperature ${ }^{\mathbf{0}} \mathbf{C}$ & 37.5 & 0.9 & 37.1 & 0.2 & 0.152 \\
Pulse /min & 89 & 10 & 93 & 17 & 0.308 \\
RR /min & 24 & 4 & 26 & 13 & 0.573 \\
\hline
\end{tabular}


Table (7): laboratory results effect on patients outcome $(n=50)$

\begin{tabular}{lccccc}
\hline & \multicolumn{2}{c}{ Discharged- Improved } & Died & p value \\
\hline WBC $(\mathbf{x 1 0} / \mathbf{c c})$ & Mean & SD & Mean & SD & 0.336 \\
Hb $(\mathbf{g m} / \mathbf{L})$ & 10.66 & 4.94 & 12.3 & 3.96 & 0.917 \\
HCT & 11.9 & 1.8 & 11.8 & 3.8 & 0.905 \\
PLT $(\mathbf{x 1 0} / \mathbf{c c})$ & 33.9 & 5.4 & 34.2 & 11.4 & 0.033 \\
pH & 256 & 97 & 182 & 93 & 0.925 \\
PO2 & 7.35 & 0.08 & 7.35 & 0.13 & 0.472 \\
PCO2 & 66.8 & 13.4 & 63.2 & 17.4 & 0.003 \\
NaCH3 & 44.8 & 20.7 & 32.7 & 6.8 & 0.114 \\
SaO2\% & 25.8 & 11.9 & 19.3 & 8.2 & 0.035 \\
Urea (mg/dL) & 88.5 & 8.9 & 80.6 & 14.8 & 0.318 \\
Creatinine (mg/dL) & 67 & 48 & 102 & 104 & 0.008 \\
Ka (mEq/L) & 1.73 & 1.1 & 3.54 & 3.63 & 0.989 \\
Na (mEq/L) & 4.4 & 1 & 4.4 & 1 & 0.910 \\
\hline SD: & 138 & 5 & 139 & 5 &
\end{tabular}

SD: standard deviation, $\mathrm{p} \leq 0.05$ is considered statistically significant, analysis done by independent $\mathrm{t}$ test

Table (8): Radiological findings effect on patients outcome $(\mathrm{n}=50)$

\begin{tabular}{lccccccc}
\hline & \multicolumn{3}{c}{ Discharged- Improved } & \multicolumn{3}{c}{ Died } \\
& Median & Min. & Max. & Median & Min. & Max. & p value \\
\hline DTF & 43.58 & 9.21 & 132.5 & 41.7 & 16.8 & 66.9 & 0.273 \\
Diaphragmatic US excursion & 1.055 & 0.327 & 2.02 & 1.325 & 0.462 & 2.42 & 0.245 \\
Diaphragmatic US thickening & 0.177 & 0.062 & 0.407 & 0.232 & 0.078 & 0.292 & 0.497 \\
\hline min: minimum max: maximum $\mathbf{p} \leq 0.05$ is statistically
\end{tabular}

min: minimum, max: maximum, $\mathrm{p} \leq 0.05$ is statistically significant analysis done by Mann Whitney test

Table (9): DTF performance of outcome of patients:

\begin{tabular}{lccccc}
\hline $\begin{array}{l}\text { lower cases indicates deaths } \\
\text { Test Result Variable(s) }\end{array}$ & Area & SE & P value & Lower Bound & Upper Bound \\
\hline DTF & 0.625 & 0.103 & 0.273 & 0.423 & 0.827 \\
\hline SE: standard error, $\mathrm{P} \leq 0.05$ is statistically significant & & & & \multicolumn{2}{c}{ 95\% Confidence Interval } \\
\hline
\end{tabular}

Table (10): DTF performance of DE and DT outcome of patients:

\begin{tabular}{lccccc}
\hline $\begin{array}{l}\text { higher indicate deaths } \\
\text { Test Result Variable(s) }\end{array}$ & Area & SE & P value & Lower Bound & Upper Bound \\
\hline Diaphragmatic US excursion & 0.631 & 0.133 & 0.245 & 0.371 & 0.891 \\
Diaphragmatic US thickening & 0.700 & 0.097 & 0.077 & 0.509 & 0.891 \\
\hline
\end{tabular}

SE: standard error, $\mathrm{P} \leq 0.05$ is statistically significant 


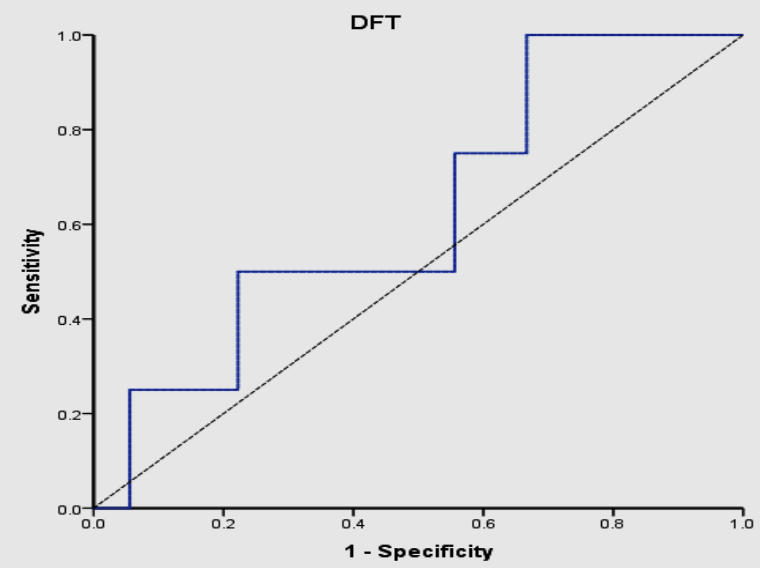

Fig.(6): ROC curve for DFT performance in detecting deaths in ICU

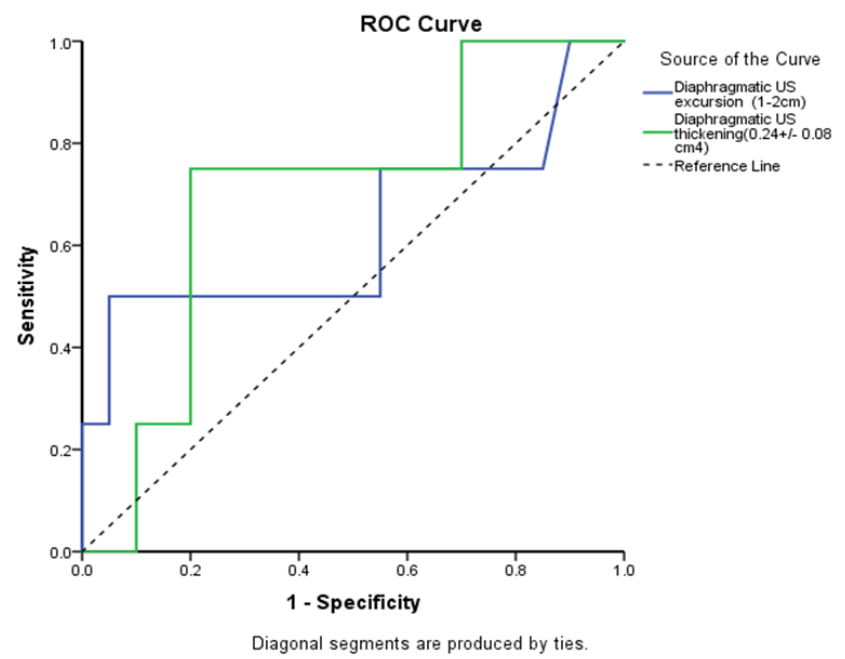

Fig.(7): ROC curve for Diaphragmatic US performance in detecting deaths in ICU

\begin{tabular}{|c|c|}
\hline $\mathrm{UC}=\mathbf{0 . 5}$ & $\begin{array}{l}\text { No discrimination (i.e., might as well flip } \\
\text { a coin) }\end{array}$ \\
\hline $0.7 \leq \mathrm{AUC}<0.8$ & Acceptable discrimination \\
\hline $0.8 \leq \mathrm{AUC}<0.9$ & Excellent discrimination \\
\hline $\mathbf{A U C} \geq \mathbf{0 . 9}$ & $\begin{array}{l}\text { Outstanding discrimination (but } \\
\text { extremely rare) }\end{array}$ \\
\hline
\end{tabular}

Table (11): how to interpret the roc curve with significant $\mathrm{p}$ value

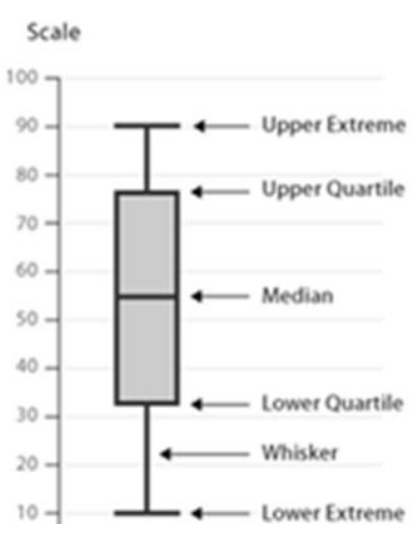

Fig.(8): Boxplot 


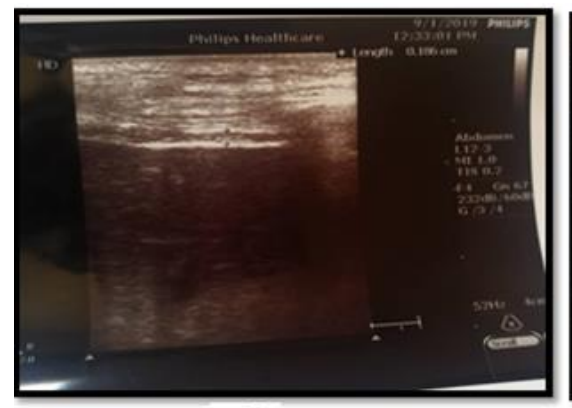

A

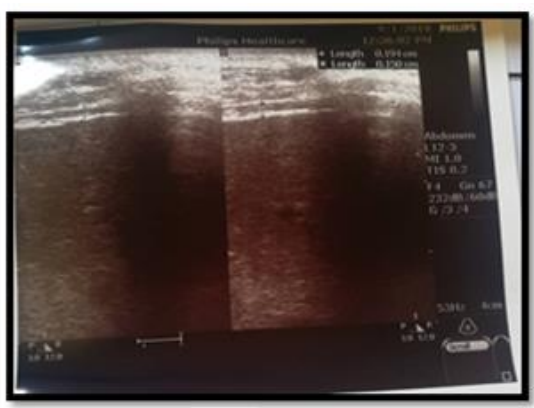

B

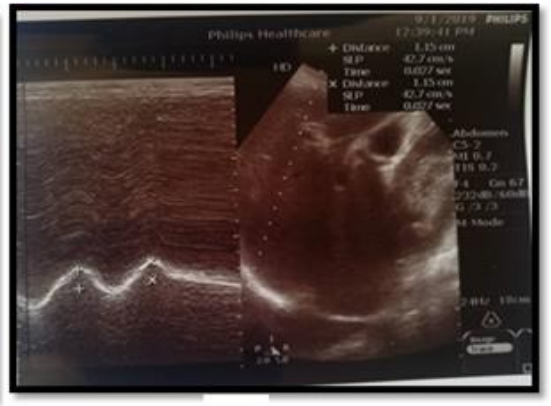

C

Fig.(9): A.diaphragm thickness at ZOA using superficial linear probe.B.diaphram thickness at end ispiration(+).and diaphragm thickness at end of expiration (*) C.diaphragm excursion by using convex (abdominal)probe.on the Lf.M mode trace, and on the Rt.2D image.

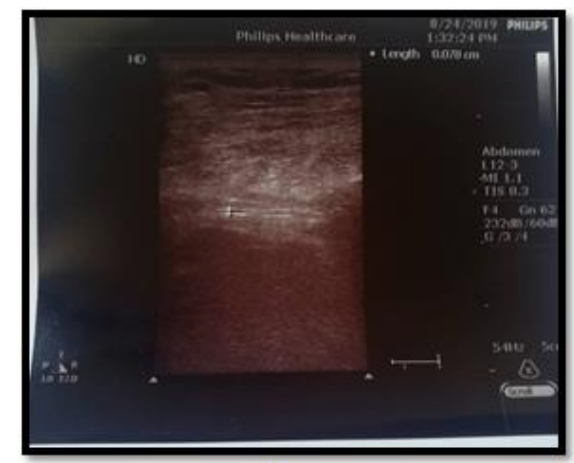

A

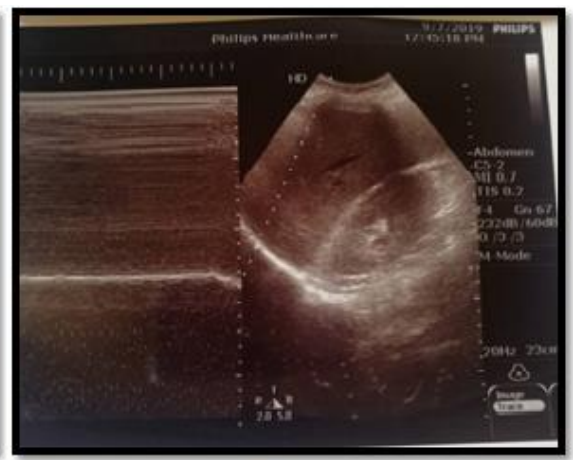

B

Fig.10: A. diaphragm thickness at ZOA using superficial linear probe. B. diaphragm thickness at end inspiration(+).and B. diaphragm excursion by using convex (abdominal) probe. on the Lf.M mode trace, and on the Rt.2D image.

\section{Discussion:}

In intensive care unit (ICU) patients, diaphragmatic dysfunction (DD) can occur on admission or during the subsequent stay. It has become a major concern in ICU patients and the subject of an increasing number of reports. To date, two major patterns of diaphragm dysfunction have been described in ICU patients. First, the diaphragm, like all organs, can be involved in the shock related generalized organ failure observed in many patients on admission to the ICU is determined by sepsis and the severity of the disease and is associated with higher mortality(10). Second, diaphragm dysfunction in critically ill patients can occur during the ICU stay in patients without prior diaphragm dysfunction. It can be a consequence of ICUacquired neuromuscular disorders. It can also be a negative consequence of mechanical ventilation per se, which is associated with a time-dependent decrease of diaphragm strength called ventilator-induced diaphragm 
dysfunction (VIDD) (11). In addition, diaphragm strength is also sensitive to ICUacquired neuromuscular disorders and hypercatabolism and corticosteroid use that are frequently observed in the ICU (12)

However, the findings of related studies are inconsistent and lack statistical power, and the clinical significances of DE and DTF still remain controversial (13)demonstrated that DE correlated well with transdiaphragmatic pressure and suggested that DE could reflect diaphragmatic dysfunction. On the contrary, it is believed that DTF rather than DE was a reliable index of respiratory effort and diaphragmatic contractile function. (14) So, in our study we trying to assess role of ultrasound of the diaphragm in ICU patients and correlate the results with clinical outcome of patients.

In this study there was no statistical significant difference between the studied groups regarding the patient age. With $p$ value 0.39 , the mean \pm SD for groups of study(improved and died ) $61.0 \pm 18.9$ and $66.4 \pm 12.4$ respectively.

This goes on hand with (15) whose study was about the role of ultrasound in assessment of diaphragmatic function in chronic obstructive pulmonary disease (COPD) patients during admission to ICU which was carried on 50 patients. Patients were divided into two groups: Group A consisted of 30 COPD patients admitted to the respiratory ICU and group B consisted of 20 COPD patients during attendance at the Chest Department. found that there was no statistical significant difference between the two groups of study regarding patient's age with $\mathrm{p}$ value 0.18 . the mean \pm SD of their age was $57 \pm 6$ and $66.2 \pm$ 7.1 respectively, which is nearly close to the age mean \pm SD in our study.

In this work there was no statistical significant difference between the studied groups regarding ultrasound measurement (DTF, DE and DT) and patient outcome with $\mathrm{p}$ value $(0.273,0.245$ and 0.497$)$ respectively.

This not go with (10) who find that there is positive correlation between ultrasound measurement (DTF, DE , and DT).and patient outcome in term of length of stay (LOS), ICU mortality and failure of weaning from mechanical ventilation with $\mathrm{p}$ value $(0.035$, 0.041 and 0.0211 ) study included 43 patients divided into 2 groups.one with DD on admission (23 patients 53\%) and other group with no DD on admission (20 patients 47\%). Also, these results are not going with(16). Their study aimed to evaluate role of diaphragmatic thickening and excursion, assessed by ultrasound, in predicting patient outcome carried out on 54 patients admitted to ICU and the results of ultrasound measurements (DE,DT and DTF)show (87.5\%, $77.5 \%, 80 \%$ and $90 \%$ sensitivity respectively and $71.5 \%, 86.6 \%, 50 \%$ and $64.3 \%$ specificity respectively. ) 
In our study there is no statistical significant difference between the two groups regarding diaphragmatic excursion. With (AUC $=0.631$, $\mathrm{SD}=0.133$ and $95 \%$ Confidence Interval $\mathrm{CI}=$ 0.371-0.891) This agrees with(14) in his study on 25 patients admitted to ICU post-surgery. and found that there is no correlation between $\mathrm{DE}$ and patient outcome with $\mathrm{p}$ value 0.981.nor was between DE and DT with $p$ value 0.450 .

In other hand these results not going with(17) who found that there is good correlation between DE and diagnosis of DD in his study on 22 patients admitted to medical ICU . s with acute respiratory failure (ARF).and diagnose DD as follow: diaphr Gmatic paralysis defined by paradoxical movement or immobility of the hemidiaphragm during unassisted deep breathing in bidimensional mode and TM mode and diaphragmatic paresis was defined by a hemidiaphragmatic excursion of less than $10 \mathrm{~mm}$ during unassisted deep breathing in bidimensional mode and TM mode.

In the same way the above result is not agree with(18)who found that Diaphragm excursion DE seems more accurate than a change in the diaphragm thickness to predict patient outcome in his study on 60 patient admitted to ICU With (AUC $=0.836$, and 95\% Confidence Interval CI = 0. 717-0. 919).
In our study there is no statistical significant difference between the two groups regarding diaphragmatic thickening fraction DTF and diaphragm thickness. With (AUC $=0.625, \mathrm{SD}$ $=0.103$ and $95 \%$ Confidence Interval $\mathrm{CI}=$ $0.423-0.827)(\mathrm{AUC}=0.700, \quad \mathrm{SD}=0.097$ and 95\% Confidence Interval CI $=0.509-0.891$ ) respectively.

This result is agree with (19) who study was designed to examine the ultrasonographic changes that occur in muscles during ICU hospitalization the study is carried out on Patients admitted to the ICU for acute respiratory failure those were enrolled prospectively and underwent serial muscle ultrasound for thickness and gray-scale assessment of the tibialis anterior, rectus femoris, abductor digiti minimi, biceps, and diaphragm muscles over 14 days. the result on diaphragm show, increased from $0.88 \mathrm{~cm}$ at baseline to $1.03 \mathrm{~cm}$ at day $14(P=0.024)$.

This result is not going with (20) who found that : Ultrasound measurements of diaphragm thickness (DT) and thickening fraction (DTF) may be useful to monitor diaphragm activity and detect diaphragm dysfunction (as atrophy) in ICU patients. their study was carried on 96 patients admitted to ICU and their results was right hemidiaphragm thickness was obtained on $95 \%$ of attempts; left hemidiaphragm measurements could not be obtained consistently. Right 
hemidiaphragm thickness measurements were highly reproducible (mean \pm SD $2.4 \pm 0.8 \mathrm{~mm}$, repeatability coefficient $0.2 \mathrm{~mm}$, reproducibility coefficient $0.4 \mathrm{~mm}$ ), particularly after marking the location of the probe. DTF measurements were only moderately reproducible (median $11 \%$, IQR $3-17 \%$, repeatability coefficient $17 \%$, reproducibility coefficient $16 \%$ ).

\section{Conclusion:}

Ultrasonography appears to be a promising tool in the evaluation of diaphragmatic function in ICU patients. It has the advantage of being fully noninvasive and is becoming widely available in an increasing number of ICUs, bypassing limitations of previously used methods for this purpose. Diaphragmatic ultrasonography provides qualitative and quantitative information regarding diaphragmatic function, as part of an overall respiratory assessment in ICU patients. Apart from clear findings, such as during diaphragmatic paralysis, ultrasonographic evaluation of diaphragmatic function may become helpful in identifying a subpopulation of ICU patients at high risk of further respiratory complications.

\section{References}

1. Yamaguti WP, Paulin E, Shibao S, Kodaira S, Chammas MC, Carvalho CR. Ultrasound evaluation of diaphragmatic mobility in different postures in healthy subjects (2007). J Bras Pneumol;33:407-13

2. Ayoub J, Milane J, Targhetta R, Prioux,J, Chamari $\mathrm{K}$, Arbeille P, et al. Diaphragm kinetics during pneumatic belt respiratory assistance: a sonographic study in Duchenne muscular dystrophy (2002). Neuromuscul Disord 12:569575

3. De Bruin PF, Ueki J, Bush A, Khan Y,Watson A, Pride NB Diaphragm thickness and inspiratory strength in patients with Duchenne muscular dystrophy (1997). Thorax 52:472-475

4. Khan J, Harrison TB, Rich MM. Mechanisms of neuromuscular dysfunction in critical illness (2008). Crit Care Clin;24:165-77.

5. Herridge MS, Batt J, Hopkins RO. The pathophysiology of long-term neuromuscular and cognitive outcomes following critical illness (2008). Crit Care Clin;24:179-99.

6. Matamis D, Soilemezi E, Tsagourias M, Akoumianaki E, Dimassi S, Boroli $F$ et al. Sonographic evaluation of the diaphragm in critically ill patients. Technique and clinical applications(2013). Intensive Care Med;39:80110.

7. Gottesman E, McCool FD. Ultrasound evaluation of the paralyzed diaphragm (1997). Am J Respir Crit Care Med.155:1570-1574

8. Beaulieu Y, Marik PE Bedside ultrasonography in the ICU: part 2 (2005).Chest 128:1766-1781

9. Tobin MJ, Laghi F, Brochard L. Role of the respiratory muscles in acute respiratory failure of COPD: lessons from weaning failure (2009). J Appl Physiol .107:962-970

10. Demoule A, Jung B, Prodanovic H, Molinari N, Chanques G, Coirault C, et al. Diaphragm dysfunction on admission to the intensive care unit. Prevalence, risk factors, and prognostic impact-a prospective study. Am J Respir Crit Care Med. 2013;188:213- 
11. Levine S, Nguyen T, Taylor N, Friscia M, Budak M, Powers SK, et al. Rapid disuse atrophy of diaphragm fibers in mechanically ventilated humans. N Engl J Med.2008;358:1327-35.

12. De Jonghe B, Bastuji-Garin S, Durand MC, Malissin I, Rodrigues P, Cerf C,et al. Respiratory weakness is associated with limb weakness and delayed weaning in critical illness. Crit Care Med. 2007;35:2007-15

13. Lerolle N, Guerot E, Dimassi S, Zegdi R, Faisy C, Fagon JY, et al. Ultrasonographic diagnostic criterion for severe diaphragmatic dysfunction after cardiac surgery. Chest. 2009 Feb; 135(2):401-407. [PubMed: 18753469]

14. Umbrello M, Formenti P, Longhi D, Andrea Galimberti, Ilaria Piva, Angelo Pezzi, et al (2015) Diaphragm ultrasound as indicator of respiratory effort in critically ill patients undergoing assisted mechanical ventilation: a pilot clinical study. Crit Care 19:161

15. Adel M Saeed, Gehan I El Assal, Tamer M Ali, Mahmoud M Hendawy. Role of ultrasound in assessment of diaphragmatic function in chronic obstructive pulmonary disease patients during weaning from mechanical ventilation. The
Egyptian journal of bronchology, 2016, Volume: 10, Issue: 2, Page : 167-172.

16. Farghaly S, Hasan AA. Diaphragm ultrasound as a new method to predict extubation outcome in mechanically ventilated patients. AustCrit Care. 2017 Jan; 30(1):37-43

17. Valette X, Seguin A, Daubin C Brunet J, Sauneuf B, Terzi N, et al. (2015) Diaphragmatic dysfunction at admission in intensive care unit: the value of diaphragmatic ultrasonography.Intensive Care Med 41(3):557-559

18. Kim WY, Suh HJ, Hong SB, Koh Y, Lim CM. Diaphragm dysfunction assessed by ultrasonography: Influence on weaning from mechanical ventilation. Crit Care Med. 2011 Dec; 39(12):2627-2630. [PubMed: 21705883]

19. Cartwright MS, Kwayisi G, Griffin LP, Sarwal A, Walker FO, Harris JM, et al (2013) Quantitative neuromuscular ultrasound in the intensive care unit. Muscle Nerve 47:255-259

20. Goligher EC, Laghi F, Detsky ME, Farias P, Murray A, Brace D, et al. Measuring diaphragm thickness with ultrasound in mechanically ventilated patients:feasibility, reproducibility and validity. Intensive Care Med. 2015;41:642-9.

To cite this article: Islam M. Alshaer, Hesham E. Elsheikh, Ahmed E. Shaalan, Marwa E. Elnaggar. The Role of Ultrasound in Assessment of Diaphragmatic Dysfunction in I.C.U Patients. BMF, 2020; 37(2): 354-368. DOI: 10.21608/bmfj.2020.17272.1073 